\title{
Carnets
}

Revue électronique d'études françaises de l'APEF

Deuxième série - 4| 2015

Regards sur Camus

\section{Outros Sísifos}

Para uma axiologia da justiça em Albert Camus e Vergílio Ferreira

\section{Miguel Filipe Mochila}

\section{(2) OpenEdition}

Journals

Edição electrónica

URL: http://journals.openedition.org/carnets/1587

DOI: $10.4000 /$ carnets. 1587

ISSN: 1646-7698

Editora

APEF

\section{Refêrencia eletrónica}

Miguel Filipe Mochila, "Outros Sísifos », Carnets [Online], Deuxième série - 4 | 2015, posto online no dia 22 setembro 2016, consultado o 01 maio 2019. URL : http://journals.openedition.org/carnets/1587 ; DOI : 10.4000/carnets. 1587

Este documento foi criado de forma automática no dia 1 Maio 2019.

\section{(c) (i) \&}

Carnets est mis à disposition selon les termes de la licence Creative Commons - Atribution - Pas d'utilisation commerciale 4.0 International. 


\title{
Outros Sísifos
}

\author{
Para uma axiologia da justiça em Albert Camus e Vergílio Ferreira
}

\author{
Miguel Filipe Mochila
}

1 A adesão do escritor português Vergílio Ferreira a um romance-problema, de temática filosófica, com incidência no questionamento existencial, encontra em Albert Camus um natural referente. Sob o signo da hegeliana consciência infeliz, desenvolve-se uma problemática própria da moderna inflexão da noção de conhecimento, à luz de uma desconfiança agudizada em ambos os autores, dada a inconcretização da pretensão epistémica de unificar um mundo contraditório que suspende a validade da apropriação racional da realidade, visto que «toute vraie connaissance, est impossible. Seules les apparences peuvent se dénombrer » (Camus, $1942: 26$ ).

2 Herdeiros da condição limitante da kantiana cisão epistemológica entre númeno e fenómeno, no que seria em Schopenhauer o mundo como vontade e representação e em Nietzsche o perspectivismo, que integram uma era da suspeita (Sarraute, 1963), ambos os autores se eivam de um subjectivismo radical que elabora a verdade como construção antropomórfica. No limite, a desconfiança na possibilidade cognoscente do Homem ancora na obstrução do próprio eu do indivíduo a si mesmo, não já entendido ao modo cartesiano, mas submerso numa cisão interior que limita o acesso à sua totalidade :

Car si j'essaie de saisir ce moi dont je m'assure, si j'essaie de le définir et de le résumer, il n'est plus qu'une eau qui coule entre mes doigts. Ce cœur même qui est le mien me restera à jamais indéfinissable. Entre la certitude que j'ai de mon existence et le contenu que j'essaie de donner à cette assurance, le fossé ne sera jamais comblé. Pour toujours, je serai étranger à moi-même (Camus, 1942 : 34).

3 A cisão do eu, grosso modo, entre uma dimensão projectiva e uma dimensão concreta, induz em ambos os autores o relato de uma experiência especular de revelação identitária que faz confluir nele, momentaneamente, ambas as faces. Esta concepção decorre de uma perspectiva afim da do estádio do espelho a que se refere Lacan (1966), formador da função do eu. Projectiva, através do confronto com a evidência da imagem própria, a experiência especular provoca o instante aparicional, através, em grande parte, do Unheimliche freudiano, esse instantâneo susto da estranheza do eu a si próprio entre desconfiança e reconhecimento. A imagem especular é uma aparência no seu sentido mais pleno em que a própria visão se percebe a si mesma como imagem. Assim, ao espelho, 
entre sujeito e imagem se gera uma simbiose tanto pelo que neles é próprio da identidade (a imagem depende do sujeito, de certa forma é-o) e da não-identidade (a imagem é um outro) :

Olhei. Quem estava diante de mim era eu próprio, reflectido no espelho do guardafato (...) $\mathrm{E}$ vi, vi os olhos, a face desse alguém que me habitava, que me era e eu jamais imaginara. Pela primeira vez eu tinha o alarme dessa viva realidade que era eu, desse ser vivo que até então vivera comigo na absoluta indiferença de apenas ser (Ferreira, $1997: 68)$.

4 A experiência desconcertante da duplicidade especular é relatada também por Camus, quando se refere ao "De même l'étranger qui, à certaines secondes, vient à notre rencontre dans une glace, le frère familier et pourtant inquiétant que nous retrouvons dans nos propres photographies" (Camus, 1942: 29). Essa experiência aparece, assim, como a visão de algo « em que agora descobria qualquer coisa mais, que me excedia e me metia medo » (Ferreira, $1997: 68)$, dada a alteridade que reflecte no próprio ser do sujeito, como reflexão que preserva a dualidade individual. Nele, a imagem da alteridade emerge, para destruí-la, na mesmidade do eu, colapsando potencialmente desse modo a ipseidade.

O espelho serve assim a Albert Camus e a Vergílio Ferreira para dar conta da experiência do momento de apreensão do outro eu que habita o mesmo, de uma alteridade fantasmática constitutiva do sujeito, núcleo de que se subtrai o sentimento trágico. A consciência da fragilidade do processo cognoscente do eu na relação consigo mesmo estabelece a valorização de uma relação patológica, tímica, com o mundo, por sobre a vivência racional. Regista-se um apelo à adesão i-mediata às coisas :

Les lignes douces de ces collines et la main du soir sur ce cœur agité m'en apprennent bien plus. Je suis revenu à mon commencement. Je comprends que si je puis par la science saisir les phénomènes et les énumérer, je ne puis pour autant appréhender le monde (Camus, 1942 : 36)

a verdade que me habita ilumina-se por dentro, e um dia vejo-a, e é exacta, indiscutível, como o sangue que me aquece (Ferreira, 1992b : 117).

Ora a impossibilidade de unificar o contraditório, quando tornada consciente, mergulha o eu no absurdo. Se «cette nostalgie d'unité, cet appétit d'absolu illustre le mouvement essentiel du drame humain» (Camus, 1942: 32), é porque agudiza a evidência da contingência como condição limitante, despojando o Homem do valor da verdade, lançando-o num vazio de sentido, bloqueando nele o que é próprio da sua vocação iminentemente teleológica. A percepção angustiada da convivência no eu, a um tempo, de « l'esprit qui désire et le monde qui déçoit, ma nostalgie d'unité, cet univers dispersé et la contradiction qui les enchaîne» (Camus, 1942: 71), conduz a uma espécie de não coincidência do Homem consigo mesmo que Ricoeur (1988) identifica com o mal e que faz do Homem, tal como para Píndaro, o sonho de uma sombra.

7 A vida transforma-se assim em "vertigem do abismo" (Ferreira, 1993: 105), um «acidente» (Ferreira, 1994: 218) que obriga a questionar, a partir da sua inverosimilhança radical, "Que é tudo agora diante de um homem que vai morrer?» (Ferreira, 1990 : 118). A abundância das condições limitantes faz assim da existência, nas perspectivas camusiana e vergiliana, uma reflexão do tédio universal, um tedium vitae tal como proposto por Schopenhauer, do eu perante o absurdo, do sem-sentido de uma existência a-télica que L'Étranger tematiza de modo exemplar. Assim, o sujeito não pode evitar o éffroi perante o silêncio dos espaços infinitos a que se referia Pascal (1969), cunhado por uma celeste eternulidade (Laforgue, 2011), projectada pela «estúpida inverosimilhança » (Ferreira, 1997 : 48) da nadificação do eu. É que « esse 'arrepio' (...) é 
mais fundo hoje que nunca » (Ferreira, 1994 : 233), pois não há já um valor no qual fixar a existência, revisitado o tópico da morte de Deus, o qual surge como " perturbação de uma ausência » (Ferreira, 1981 : 121). Estamos pois próximos do conteúdo do absurdo, segundo Camus : "Un homme sans espoir et conscient de l'être n'appartient plus à l'avenir » (Camus, 1942: 50). Esta hopelessness (Lodge, 1993) da condição humana resulta de uma paradoxalidade que nenhuma síntese resolverá, tal como relatada por Pascal, segundo o qual o homem é « un néant à l'égard de l'infini, un tout à l'égard du néant, un milieu entre rien et tout » (Pascal, 1969 : 136).

8 A morte radicaliza-se e a consciencialização da existência própria reveste-se de um pendor trágico :

E todavia, agora que me descubro vivo, agora que me penso, me sinto, me projecto nesta noite de vento, de estrelas, agora que me sei desde uma distância infinita, me reconheço não limitado por nada mas presente a mim próprio como se fosse o próprio mundo que sou eu, agora nada entendo da minha contingência. Como pensar que 'eu poderia não existir'? Quando digo 'eu', já estou vivo... Como entender que esta iluminação que sou eu, esta evidência axiomática que é a minha presença a mim próprio, esta fulguração sem princípio que é eu estar sendo, como entender que pudesse 'não existir' ? (Ferreira, 1997 : 49-50).

O sujeito sente assim, heideggerianamente, a morte já não como um dado mas como uma negatividade, como uma falta de ser, incorporando a vida como desejo e desenvolvendo aquela consciência angustiada mergulhada numa situação que Odier (1961) designa de sphaleia, de confronto com a diluição de uma promessa que as condições limitantes negam ao eu e que Camus concretiza a um nível histórico :

Chaque génération, sans doute, se croit vouée à refaire le monde. La mien ne sait pourtant qu'elle ne le refera pas. Mais sa tâche est peut-être plus grande. Elle consiste à empêcher que le monde se défasse. Héritière d'une histoire corrompue où se mêlent les révolutions déchues, les techniques devenues folles, les dieux morts et les idéologies exténuées, où de médiocres pouvoirs peuvent aujourd'huit out détruire mais ne savent plus convaincre, où l'intelligence s'est abaissée jusqu'à se faire la servante de la haine et de l'oppression, cette génération a dû, en ellemême et autour d'elle, restaurer, à partir de ses seules négations, un peu de ce qui fait la dignité de vivre et de mourir (Camus, 1958 : 17-18).

10 A realidade oferece-se agora ao Homem, no entanto, como domínio do desconforto. A icónica notícia da morte de uma Mãe, como de um Pai ou de um Deus, que L'Étranger anuncia, multiplica-se nas narrativas de Vergílio Ferreira como motivo do desamparo suscitado por uma perda ou disjunção que lança o sujeito no espaço amorfo de um mundo por esculpir. Um certo « cansaço de ser homem fora do útero materno » (Ferreira, 1983b : 200) desembocará inevitavelmente num apelo da tanatologia, em torno de uma morte que, na linha de Simmel, Scheler, Heidegger, Jaspers, Sartre ou Marcel, descobre na morte uma autêntica situação-limite. Assim absolutizada, a morte existencializa-se, povoando o horizonte quotidiano do ser humano que se vê forçado a fazer um contínuo balanço da vida, conferindo a dita situação-limite uma dimensão hermenêutica.

11 É onde a morte se faz um a priori (Scheler, 1968) ou interior à vida (Simmel, 1986). Explorada fundamentalmente por Heidegger, a dimensão hermenêutica da morte radicaliza a questão do seu sentido, mais do que do seu fundamento, não se tratando já de identificar o quê da morte, mas de resolver, resolvendo-se o sujeito nisso, o seu para quê. As obras de Albert Camus e de Vergílio Ferreira, justamente, consubstanciando esta experiência da interiorização do tanatológico à vida, feita sub specie mortalis, configuram uma meditatio mortis, segundo a qual a morte não representa já apenas um factum mas 
ainda um interpretativum, através de uma consciencialização antecipadora da sua realidade que lhe confere um valor apofântico, mediante a exploração de uma existência referida ao sentido.

A antecipação da morte, projectada como nadificação, despoleta no indivíduo a evidência do sem-sentido de tudo, promovendo desse modo a tentação do suicídio como afirmação de domínio humano sobre os seus próprios limites. Feito o principal e em limite único problema filosófico, tal como defende Camus - a saber : o de afirmar se viver vale ou não a pena - a pretensa resolução suicida resulta de um horror vacui que instala no homem a dúvida, suscitada por um tempo sem verdades que ordenassem a existência individual, um tempo de « desagasalho » (Jaspers, $1968: 223)$ cunhado pela aniquilação de todos os referentes.

E no entanto o suicídio é recusado por ambos os autores. Contra ele, Camus reivindica « la seule dignité de l'homme : la révolte tenace contre sa condition, la persévérance dans un effort tenu pour stérile » (Camus, 1942: 156), e Vergílio Ferreira afirma que «Estar vivo não é suicidar-me. Não renego: assumo" (Ferreira, 1983: 151). Aporta-se aqui directamente na dimensão ética do pensamento camusiano, a qual sobremaneira interessou a Vergílio Ferreira, que observava :

Recusada uma Transcendência, o moralismo de Camus debate-se entre o reconhecimento do absurdo e a categórica necessidade de o superar, entre a 'razão lúcida que constata os seus limites' e a imperiosa obrigação de ordenar a vida (Ferreira, 1992 : 137)

Porque não basta denunciar o vazio do mundo - e Camus o reconheceu explicitamente. Denunciar o vazio é um ponto de partida metodológico (Ferreira, $1991: 259)$

uma espécie de 'dúvida metódica'. Ao niilismo sucede a tentativa de uma superação. A negação equilibra-se agora com a afirmação, o ‘não' com o ‘sim' (Ferreira, 1991 : 284).

14 É necessário, por conseguinte, promover a enárgeia ou evidentia da nadificação, ao modo da Grundbefindlichkeit heideggeriana, de maneira a estimular a autorreflexividade práxica. Dita antecipação permite justamente « integrar a morte na vida (Ferreira, 1990: 122), pois «nada de grande se pensa sobre a vida, que não pressuponha o pensamento da morte » (Ferreira, 1997b : 313), até porque é o intento de projectar a nadificação do ego que agudiza o desejo de preservação do mesmo: "Acaso, na verdade, uma vida seria assim tão valiosa se precisamente não houvesse morte?» (Ferreira, 1991: 74). Procurando ambos os autores fundamentalmente justificar a vida mediante a elaboração de um projecto ético, surge a necessidade de encontrar um valor, aquela verdade pela qual possa viver e morrer que Kierkegaard se exigia, para adequar a vida à morte, uma « ideia-força que ordena uma vida, a orienta, se impõe como a evidência, como tudo o que é indiscutível » (Ferreira, 1990a : 165), «m mais que nós, (...) um Valor que nos absorva » (Ferreira, 1994 : 113), com o fim de « salvar do amontoado de cinzas a pequena brasa viva que acenda outras fogueiras » (Ferreira, $1983: 94)$.

O eco camusiano das palavras de Vergílio Ferreira é evidente. Perante uma situação de abandono cósmico, há uma questão ética que se coloca ao homem, obrigado a eleger os valores para ordenar a sua vida : «ser livre é instaurar uma ética, a nossa liberdade vazia não pode ignorar os Valores; ser livre é por força escolher " (Ferreira, 1994: 357). Em reminiscência ainda sartriana, Vergílio Ferreira dá assim conta do absurdo como situação que gera uma tomada de posição, constituindo-se a partir dela uma axiologia em que o sujeito se origine: "Partindo do nada, sem leis inscritas numa vontade divina, 
abandonado a si mesmo, o homem tem de constituir-se uma Tábua de Valores e de assumi-los em responsabilidade » (Ferreira, $1970: 210$ ).

A procura de um projecto reinstaurador já não do mas de um sentido segue em ambos os autores derivas aproximadas. É o caso de uma afirmação da procura mais ou menos errante de um espaço para ser, contra o sentimento de placelessness tal como definido por Lutwack (1984), de estrangeiridade que instaura uma topofobia associada aos lugares de cerco, como o daquela « cidade pequena que repetimos num círculo de prisão » (Ferreira, $1992 b$ : 35) que ecoa La Peste, na deambulação permanente que intenta fixar um espaço topofílico, segundo termo de Bachelard, um espaço de familiaridade que mantém uma relação tímica com o sujeito (Bertrand, 1985 : 124-125) e que encontra na comum vocação mediterrânica uma ardente resposta, no apelo extático do sol, do Verão, do mar.

É ainda o caso da valorização do presente - « La vraie générosité envers l'avenir consiste à tout donner au présent » (Camus, 1951 : 375), e da sua vivência em plenitude, encontro do tempo com a eternidade, na definição de Kierkegaard, junção de origem e projeto, segundo Heidegger, esse aqui-e-agora em que « me descubro vivo, me penso, me sinto, me projecto na noite de vento, de estrelas, me sei desde uma distância infinita, me reconheço não iluminado por nada mas presente a mim próprio » (Ferreira, $1997: 44$ ), pois « Car s'il y a un péché contre la vie, ce n'est peut être pas tant d'en désespérer que d'espérer une autre vie, et se dérober à l'implacable grandeur de celle-ci »(Camus, 1959 : 65).

18 E é ainda o caso, finalmente, da entrega à comunhão, condição ética da revelação identitária (Levinas, 1985), que fundamentaria o apelo a uma consciência dual tal como formulada por Jean Hyppolite (1947) ou Martin Buber (1982), na medida em que, infernalmente, « o olhar dos outros é que nos dá a consciência de sermos ", « irremovível condição para nos sabermos e assumirmos » (Ferreira, 1970: 145). O desafio ético, no âmbito da ética do dom de Derrida, o qual afirma que «Il n'y a pas d'éthique sans présence de l'autre» (apud Pavel, 1988: 15-16), proposto pelo dialogismo de Levinas (1982), segundo o qual a impossível comunicação constitui uma condição para que o amor, o cuidado do outro, seja efectivo, é assim previamente aceite pelos autores, que encontram no desejo da transcendência da subjectividade, mais do que na sua possibilidade, a fundamentação de um comportamento desejável que encontra na revolta a sua derradeira frente. Porque a revolta é « quelque chose qui déborde l'individu dans la mesure où elle le tire de sa solitude supposée et le fournit d'une raison d'agir » (Camus, 1951 : 28), o sofrimento que o absurdo suscitara no indivíduo toma então « conscience d'être collective, elle est l'aventure de tous. Le mal qui éprouvait un seul homme devient peste collective ", transforma-se numa « comunidade de condição que se revela de dentro de cada um de nós » (Ferreira, 1992 : 233) e que grita com Karamazov : se não forem salvos todos, de que serve a salvação de um só?

19 Não crentes já em nenhuma espécie de salvação concreta, Albert Camus e Vergílio Ferreira articulam ainda assim um discurso resistivo e imanentista, na procura de descobrir no Homem «Quelque chose a du sens, enfin, que nous devons conquérir sur le non-sens » (Camus, $1951:$ 355). Assim, conforme esclarece o autor francês, as teorias da revolta «ne sont pas des formules d'optimisme, dont nous n'avons que faire dans l'extrémité de notre malheur, mais des paroles de courage et d'intelligence " (Camus, 1951: 374). Num apelo ao orgulho, e porque «Le spectacle de l'orgueil humain est inégalable ( (Camus, 1942: 79), porque é necessário «mourir irréconcilié et non pas de plein gré » (Camus, 1942: 78), Vergílio Ferreira prolongaria a solução camusiana que consiste na persistência de uma «déraison, devant une condition injuste et 
incompréhensible » (Camus, 1951 : 21). Trata-se, agora, de « viver sem esperança (mas não em desespero), em recusa (mas não em renúncia) e em insatisfação (mas não em inquietação juvenil)»(Ferreira, 1991: 283). Recusando assim o encerramento da metafísica à negação do homem e do humanismo, pelo contrário se assume este como o valor axiomático central.

Eis onde surge a vida como " afirmação total que nada pode pôr em questão » (Ferreira, 1994 : 33), como valor que « devemos salvar para salvarmos o pouco de grandeza que nos coube » (Ferreira, 1994 : 193). Projecto ético de defesa da vida como máximo valor, surge a proposta da heroicidade resistiva ou sísifica do Homem face à iminência da nadificação do ego : « é nosso dever mobilizar todo o esforço de uma intensa atenção para que o melhor do universo se não destrua. Porque nesse mínimo está o máximo concebível da grandeza e do milagre. A vida. Tão pouco e tão tanto » (Ferreira, 1998 : 280). A defesa da vida através de uma existência heróica constitui assim « uma razão bastante para o homem encontrar o seu lugar no mundo e a inquietação que nos domina encontrar o seu repouso na própria maravilha de se estar vivo » (Ferreira, 1995 : 66), mediante uma aposta num máximo de intensidade e de profundidade, potenciando o kairos, a possibilidade da apreensão dos instantes de alegrias breves, assentes no deslumbrado facto de existir apenas.

Não obstante a subsistência do fatum, há ainda, por conseguinte, conforme observa Vergílio Ferreira, "a liberdade de ir contra isso pela hybris que é um acto de orgulho » (Ferreira, $1987: 388$ ). Assim, o homem revela-se existencialmente protector da dignitas que o substancializa em grandeza e em intensidade - e já não em finalidade - como caso exemplar na resistência à morte. Habitante dessa falha essencial na justiça do cosmos, resolve-a numa paradoxal lucidez trágica da sua inevitabilidade e da necessidade de, não obstante essa inglória tragicidade, investir na obstinação de rejeitá-la. Através de uma " visão total e resistente do mundo " (Ferreira, 2010 : 176), ele persegue a sobrevivência, ainda, dos « sentimentos nobres do homem, (...) o milagre da 'aventura', ideal do moderno quixotismo (...) o esforço de uma dignificação humana » (Ferreira, $2010: 176)$, porque sobra ainda « um meio de lutar - até ao fim -, com os restos de dignidade que nem a morte vence, porque a justiça não morre » (Ferreira, 2010 : 176). Assim, o estóico resolvese num contra-estóico, por ser a aceitação da morte recusa da sua justiça, apelando à cisão fundamental com a ordem cósmica, na prolongação não propriamente de uma violência esperançada, mas de uma consciência revoltada, fomentadora de uma existência heróica, tal como sustentado por Schopenhauer.

Considerando que « só vale a pena na vida o que for contra a morte, contra a qual não temos verdade nenhuma " (Ferreira, 1997a: 225), "porque o erro e a degradação e a injustiça não devem ter razão » (Ferreira, 1998 : 343), Vergílio Ferreira, assim iluminado por Albert Camus, ultrapassa o ser-para-a-morte mediante o ser-contra-ela que beberia igualmente, e de modo mais directo, em Malraux. Imaginar Sísifo feliz é reconhecer ainda que «Il n'est pas de destin qui ne se surmonte par le mépris » (Camus, 1942: 166). E se a substância do ser habita o seu conatus, a permanência do desiderativo, da luta do Homem para ser, não o endereçando à verdade, endereça-o não obstante à dignidade. É onde essa "clairvoyance qui devait faire son tourment consomme du même coup sa victoire" (Camus, 1942 : 166). Porque, se é o nada que nos está reservado, é preciso fazer com que isso seja uma injustiça, segundo apelo de Sénancour. Que a morte nos mate sem que nos deixemos matar. Sem que nos deixemos morrer. 


\section{BIBLIOGRAFIA}

BETRAND, Denis (1985). L'espace et le sens. Paris/Amsterdam: Hadès/Benjamins.

BUBER, Martin (1982). La Vie en Dialogue. Paris : Aubier Montaigne.

CAMUS, Albert (1959). Noces suivi de L'Été. Paris: Gallimard, « Folio ».

Camus, Albert (1958). Discours de Suède. Paris : Gallimard, « NRF ».

CAMUS, Albert (1951). L’Homme Révolté. Paris : Gallimard, « NRF ».

CAmus, Albert (1942). Le Mythe de Sisyphe. Essai sur l'absurde. Paris : Gallimard, « Les essais ».

FERREIRA, Vergílio (2010). Promessa. Lisboa : Quetzal.

FERREIRA, Vergílio (1998). Espaço do Invisível 5. Lisboa : Bertrand Editora.

FERREIRA, Vergílio (1997). Aparição. Lisboa : Bertrand Editora.

FERREIRA, Vergílio (1997a). Em Nome da Terra. Lisboa : Bertrand Editora.

FERREIRA, Vergílio (1997b). Pensar. Lisboa : Bertrand Editora.

FERREIRA, Vergílio (1995). Espaço do Invisível 4. Lisboa : Bertrand Editora.

FERREIRA, Vergílio (1994). Invocação ao Meu Corpo. Lisboa : Bertrand Editora.

FERREIRA, Vergílio (1993). Rápida a Sombra. Lisboa : Bertrand Editora.

FERREIRA, Vergílio (1992a). Espaço do Invisível 3. Lisboa : Bertrand Editora.

FERREIRA, Vergílio (1992b). Estrela Polar. Lisboa : Bertrand Editora.

FERREIRA, Vergílio (1991). Espaço do Invisível 2. Lisboa : Bertrand Editora.

FERREIRA, Vergílio (1990). Apelo da Noite. Lisboa : Bertrand Editora.

FERREIRA, Vergílio (1990a). Espaço do Invisível. Lisboa : Bertrand Editora.

FERREIRA, Vergílio (1987). Conta-Corrente V. Lisboa : Bertrand Editora.

FERREIRA, Vergílio (1983a). Cântico Final. Lisboa : Bertrand Editora.

FERREIRA, Vergílio (1983b). Nítido Nulo. Lisboa : Bertrand Editora.

FERREIRA, Vergílio (1970). «Da Fenomenologia a Sartre », in Jean-Paul Sartre. O Existencialismo é um Humanismo. Lisboa : Editorial Presença, pp. 11-204.

FERREIRA, Vergílio (1981). Um Escritor Apresenta-se. Lisboa : Imprensa Nacional-Casa da Moeda.

HIPPOLYTE, Jean (1947). Introduction à la philosophie de l'histoire de Hegel. Paris: Rivière.

JASPERS, Karl (1968). A Situação Espiritual do Nosso Tempo. Lisboa : Moraes Editores.

LACAN, Jacques (1966). Écrits - I. Paris : Seuil.

LAFORGUE, Jules (2011). Essential Poems and Prose of Jules Laforgue. Boston : Black Widow Press.

LEVINAS, Emmanuel (1985). Le temps et l'autre. Paris : Quadrige/Presses Universitaires de France. 
LUTWACK, Leonard (1984). The role of space in literature. New York: Syracusa University Press.

ODIER, Charles (1961). La angustia y el pensamiento mágico. México : Fondo de Cultura Económica.

PAVEL, Thomas (1988). Le Mirage Linguistique. Paris : Éditions de Minuit.

PASCAL, Blaise (1969). Pensées. Paris : Gallimard.

RICOEUR, Paul (1988). Philosophie de la volonté II. Finitude et culpabilité. Paris : Aubier.

SARRAUTE, Nathalie (1963). A Era da Suspeita. Lisboa : Guimarães Editores.

SCHELER, Max (1968). El puesto del hombre en el cosmos. Buenos Aires : Losada.

SIMMEL, Georg (1986). El individuo y la libertad. Ensayos de crítica de la cultura. Barcelona : Península.

\section{RESUMOS}

A adesão de Vergílio Ferreira a um « romance-problema », de temática filosófica, com incidência no questionamento existencial, encontra em Albert Camus um referente natural. Sob o signo da hegeliana consciência infeliz, desenvolve-se uma problemática própria da ironia trágica (tal como teorizada por Schlegel), segundo a qual o Homem pressente por fulgurações a discordância patética entre o plano do real em que se move e aqueloutro do ideal que projecta nas suas diversas experiências do mundo. A problemática do seu estar nele, no seu constituir, heideggerianamente, um ser-para-a-morte, funda, nessa moeda irónica, o difícil esclarecimento entre uma poética da esperança na revelação de um sentido e de um encontro do Homem consigo mesmo, do seu caminhar desde a face real para a face ideal que o mobiliza, e a absoluta garantia do seu fracasso que lhe aponta directamente ao coração a voragem do nada. A náusea absorve-o, então, desde uma sucessão de disjunções fundamentais, entre as quais ele se (não) decide, no sentido da decisão existencial a que se referia Jaspers. Em ambas as obras transparece a dimensão paradoxal do sujeito que a enforma como espaço para a angústia.

The attachment of Vergílio Ferreira to a «problem-novel» with a philosophical theme, focusing on the existential question, finds in Albert Camus a natural referent. Under the sign of the Hegelian unhappy consciousness, a problematic is developed according to which the human being senses through flashes, the pathetic discrepancy between the actual plane where he moves and that other, the ideal plane, that is projected in his various experiences of the world. The problematic of how to be in his being, in its form, heideggerian, a being-towards-death, routes the difficult clarification between a poetics of hope in the revelation of meaning and the encounter of man with himself, a march from the real plane to the ideal plane that mobilizes him, and the absolute assurance of its failure pointing directly to his heart in a maelstrom of nothingness. Both works reveal the paradoxical dimension of the subject that envelop him as a momentum for anguish.

\section{ÍNDICE}

Keywords: problem-novel, otherness, thanatology, revolt, heroism

Palavras-chave: romance problema, alteridade, tanatologia, revolta, heroísmo 
AUTOR

MIGUEL FILIPE MOCHILA

Un. d'Évora

miguel.filipe.mochila[at]gmail.com 